\title{
OBTENÇÃO E CARACTERIZAÇÃO DE LIGAS DE Fe-W DESTINADAS À PROTEÇÃo ANTICORROSIVA
}

\author{
F. L. MOREIRA ${ }^{1 *}$, M. B. PORTO ${ }^{1}$, M. G. A. VIEIRA ${ }^{1}$, M. G. C. SILVA ${ }^{1}$, A. F. ALMEIDA \\ NETO $^{1}$ \\ ${ }^{1}$ Universidade Estadual de Campinas, Faculdade de Engenharia Química \\ e-mail: fernandoeq012@gmail.com
}

\begin{abstract}
RESUMO
Neste trabalho foram sintetizadas, por eletrodeposição, ligas de tungstênio usando o ferro como metal indutor. Os ensaios de eletrodeposição foram realizados segundo um planejamento experimental $2^{3}$ com 3 pontos centrais, de modo que foi analisada a influência da densidade de corrente elétrica, concentração do ferro no banho eletrolítico e temperatura sobre a eficiência de eletrodeposição. As melhores ligas obtidas foram caracterizadas utilizando microscopia eletrônica de varredura (MEV), difração de Raios $\mathrm{X}$ (DRX) e espectroscopia de absorção de infravermelho (FTIR). A maior eficiência de deposição obtida foi de aproximadamente $50 \%$ e as ligas caracterizadas apresentaram alto grau de pureza e baixa cristalinidade, sendo predominantemente amorfas.
\end{abstract}

\section{INTRODUÇÃO}

Seja na indústria química, nos meios de transportes e de telecomunicações, na medicina e até mesmo em obras de arte, a corrosão gera enormes problemas. Em relação à indústria química, ela é responsável pelo custo de substituição de peças, paralisações para limpeza e manutenção, perda e contaminação de produtos, diminuição da eficiência, dimensionamento exagerado de equipamentos e até por possíveis acidentes. Só no Brasil, são estimados em bilhões de reais os prejuízos financeiros gerados por ela.

A utilização de revestimentos protetores é uma boa alternativa para, além de coibir a corrosão, melhorar as características físicoquímicas da própria superfície revestida. Nesse sentido, a eletrodeposição é um método simples e barato de recobrir os materiais com esses revestimentos. Ressalta-se que em indústrias com processos galvanoplásticos, como produção de bijuterias, os próprios resíduos industriais podem ser utilizados como matéria-prima para os banhos eletrolíticos, uma vez que apresentam metais em sua composição.

O tungstênio é um metal que apresenta características muito boas: alta resistência à corrosão e dureza mesmo em elevadas temperaturas, alta densidade, o menor coeficiente de dilatação térmica entre todos os metais e alta condutividade térmica (SAKITA et al., 2013). As ligas formadas pelo tungstênio mantêm essas boas propriedades e, sobretudo, apresentam resistência à corrosão acima da média (BHATTARAI et al., 1998).

Contudo, eletrodepositar este metal na sua forma pura a partir de sua solução aquosa não é possível. Como citado por Tharamani et al. (2006), isto é devido a codeposição do hidrogênio e também ao fato de o tungstênio ser um metal relutante em se eletrodepositar. Todavia, é possível depositar o tungstênio com o ferro, níquel ou cobalto (DELPHINE, JAYACHANDRAN e SANJEEVIRAJA, 2003 e SANTANA, PRASAD e SANTANA, 2003). Segundo Brenner (1963), em uma 
situação como esta, em que o metal precisa da presença de outro para se eletrodepositar, formando assim uma liga, tem-se uma codeposição induzida.

Conforme os trabalhos de Donten, Cesiulis e Stojek (2000), as ligas de ferro e tungstênio, investigadas neste trabalho, são, em comparação com as ligas formadas entre tungstênio e níquel e tungstênio e cobalto, mais duras e se aderem melhor ao aço. Devido à sua elevada dureza, as ligas de W$\mathrm{Fe}$ podem substituir com sucesso aquelas formadas por cromo, que são tóxicas e trazem prejuízo ao meio ambiente devido à presença do cromo hexavalente.

\section{METODOLOGIA}

\subsection{Substrato}

Em uma eletrodeposição, o substrato (material a ser protegido) é o cátodo da célula eletrolítica, ou seja, onde ocorre a deposição da liga. Todas as ligas foram depositadas sobre uma placa de cobre com $2 \mathrm{~cm}$ de lado de um quadrado, resultando em $8 \mathrm{~cm}^{2}$ de área. O substrato foi acoplado ao eletrodo rotatório por uma haste, conforme a Figura 1.

Figura 1 - Substrato de cobre com haste para acoplamento

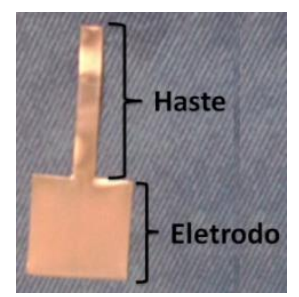

Antes das eletrodeposições, cada superfície de cobre foi rigorosamente polida e depois tratada quimicamente, inicialmente com $\mathrm{H}_{2} \mathrm{SO}_{4} 1 \%$, para ativação da superfície, e depois com $\mathrm{NaOH} 10 \%$, para eliminar eventuais gorduras decorrentes da manipulação da placa.

\subsection{Banhos Eletrolíticos}

Os banhos utilizados foram preparados com $\mathrm{Na}_{2} \mathrm{WO}_{4} \quad 0,3 \mathrm{~mol} / \mathrm{L}$ como fonte de tungstênio. Também foram utilizados $\mathrm{Na}_{2} \mathrm{~B}_{4} \mathrm{O}_{7} 3,75.10^{-2} \mathrm{~mol} / \mathrm{L}$ como fonte de boro, para se obter uma liga amorfa; 1dodecilsulfato-Na $1,04.10^{-4} \mathrm{~mol} / \mathrm{L}$, para que o $\mathrm{H}_{2}$ liberado na eletrodeposição se desprenda rapidamente e não forme bolhas na liga; e $\left(\mathrm{NH}_{4}\right)_{2} \mathrm{SO}_{4} \quad 1,287.10^{-1} \mathrm{~mol} / \mathrm{L}$ para dar estabilidade ao banho. As eletrodeposições da liga de $\mathrm{Fe}-\mathrm{W}$ foram realizadas com soluções de $\mathrm{FeSO}_{4}$ como fonte de ferro e $\left(\mathrm{NH}_{4}\right)_{2} \mathrm{C}_{6} \mathrm{H}_{6} \mathrm{O}_{7} \quad 0,3 \mathrm{~mol} / \mathrm{L}$ como seu agente complexante. Foram feitas eletrodeposições com concentração de $\mathrm{FeSO}_{4}$ de 0,01, 0,055 e $0,1 \mathrm{~mol} / \mathrm{L}$

Para os ensaios utilizou-se um eletrodo rotatório, um potenciostato para controle da diferença de potencial elétrico entre o eletrodo de trabalho e o contraeletrodo e um banho termostático para controle da temperatura. Foram feitas eletrodeposições com densidade de corrente elétrica de 10,30 e $50 \mathrm{~mA} / \mathrm{cm}^{2}$ e temperatura de $25,42,5$ e $60{ }^{\circ} \mathrm{C}$. Todos os ensaios foram realizados com rotação catódica de $30 \mathrm{rpm}$. O potenciostato foi usado de forma galvanostática e o $\mathrm{pH}$ dos banhos foi de aproximadamente $6 . \mathrm{O}$ contraeletrodo foi uma malha cilíndrica oca de platina, como mostrado na Figura 2. Cada eletrólise durou 60 minutos.

Figura 2 - Representação esquemática da célula eletrolítica

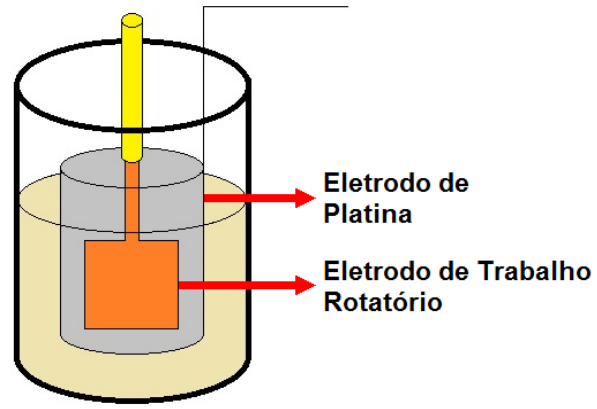




\subsection{Eficiência de Eletrodeposição}

A eficiência de deposição quantifica a carga elétrica utilizada em relação à disponível para a realização da eletrólise. No caso das ligas de $\mathrm{Fe}-\mathrm{W}$, a eficiência de deposição deve ser calculada a partir da Equação 1:

$$
\varepsilon=\frac{m \cdot F}{i \cdot t} \sum \frac{n_{j} \cdot w_{j}}{M_{j}}
$$

\subsection{Planejamento Experimental}

Foi realizado um planejamento fatorial experimental $2^{3}$ para avaliar o processo de eletrodeposição da liga de Fe-W, analisandose a influência da concentração inicial de ferro no banho $\left(\mathrm{C}_{\mathrm{Fe}}\right)$, da densidade de corrente elétrica (I) e da temperatura do banho (T) sobre a eficiência de deposição $(\varepsilon)$. O método envolveu $2^{3}=8$ experimentos mais 3 no ponto central, totalizando 11 ensaios. A Tabela 1 apresenta as variáveis de entrada utilizadas no planejamento fatorial, suas codificações e os níveis reais de cada variável do sistema.

Tabela 1 - Níveis reais e codificados das variáveis do planejamento fatorial $2^{3}$

\begin{tabular}{|c|c|c|c|}
\hline Variáveis Níveis & -1 & 0 & +1 \\
\hline $\mathrm{C}_{\mathrm{Fe}}(\mathrm{mol} / \mathrm{L})$ & 0,01 & 0,055 & 0,1 \\
\hline $\mathrm{I}\left(\mathrm{mA} / \mathrm{cm}^{2}\right)$ & 10 & 30 & 50 \\
\hline $\mathrm{T}\left({ }^{\circ} \mathrm{C}\right)$ & 25 & 42,5 & 60 \\
\hline
\end{tabular}

\subsection{Caracterização das Ligas}

As amostras de substrato contendo as ligas de tungstênio foram caracterizadas por Difração de Raios X (DRX), Espectroscopia de Infravermelho com Transformada de Fourier (FTIR) e Microscopia Eletrônica de Varredura (MEV) com Análise Química por Energia Dispersiva de Raios X (EDX). O DRX foi obtido em um aparelho da marca Philips, modelo X'PERT com radiação K $\alpha$ do cobre, tensão de $40 \mathrm{kV}$, corrente de $40 \mathrm{~mA}$, comprimento de onda $1,52 \AA$, tamanho do passo $0,022 \theta$ e tempo por passo de 1 segundo. $\mathrm{O}$ espectro de FTIR foi determinado em Espectrômetro de Infravermelho da marca Thermo Scientific, modelo Nicolet 6700 (Madison/USA). As análises de FTIR foram feitas no modo Refletância na faixa de 4000$650 \mathrm{~cm}^{-1}$ e resolução $4 \mathrm{~cm}^{-1}$. As micrografias dos substratos de cobre contendo as ligas metálicas de tungstênio foram obtidas no microscópio eletrônico de varredura (MEV) da marca LEO, modelo LEO 440i com detector de Energia Dispersiva de Raios X (EDX).

\section{RESULTADOS E DISCUSSÃO}

A Tabela 2 mostra as eficiências obtidas nos ensaios de eletrodeposição $(\varepsilon)$, realizados em ordem aleatória. Para a eletrodeposição da liga de $\mathrm{Fe}-\mathrm{W}$, os valores ótimos de concentração de $\mathrm{FeSO}_{4}\left(\mathrm{C}_{\mathrm{Fe}}\right)$, densidade de corrente elétrica (I) e temperatura (T) do banho foram $\mathrm{C}_{\mathrm{Fe}}=0,1 \mathrm{~mol} / \mathrm{L}, \mathrm{I}=10 \mathrm{~mA} / \mathrm{cm}^{2}$ e $\mathrm{T}=25^{\circ} \mathrm{C}$. O valor máximo alcançado de eficiência de deposição catódica, nestas condições, foi de aproximadamente $50 \%$.

Tabela 2 - Eficiência de deposição

\begin{tabular}{ccccc}
\hline Exp. & $\mathrm{C}_{\mathrm{Fe}}$ & $\mathrm{I}$ & $\mathrm{T}$ & $\varepsilon(\%)$ \\
\hline 1 & -1 & -1 & -1 & 9,65 \\
2 & +1 & -1 & -1 & 50,05 \\
3 & -1 & +1 & -1 & 7,99 \\
4 & +1 & +1 & -1 & 37,5 \\
5 & -1 & -1 & +1 & 11,91 \\
6 & +1 & -1 & +1 & 18,19 \\
7 & -1 & +1 & +1 & 10,68 \\
8 & +1 & +1 & +1 & 35,69 \\
9 & 0 & 0 & 0 & 40,02 \\
10 & 0 & 0 & 0 & 39,95 \\
11 & 0 & 0 & 0 & 35,29 \\
\hline
\end{tabular}

Com um nível de confiança de 95\%, pode-se afirmar que a concentração de ferro em solução foi a variável que obteve maior influência estatística sobre a eficiência de deposição. O modelo fornecido pela análise 
ajusta-se aos dados experimentais de eficiência do processo de eletrodeposição da liga de $\mathrm{Fe}-\mathrm{W}$ conforme a Equação 2.

$\varepsilon=281 \cdot \mathrm{C}_{\mathrm{Fe}}+13,54$

$\mathrm{Na}$ Figura 3 estão apresentadas as interações entre a variação de concentração de sulfato de ferro e a variação de temperatura do banho eletrolítico, tendo como resposta a eficiência de deposição.

Figura 3 - Superfície de resposta da eficiência de deposição em função da temperatura e da concentração de sulfato de ferro

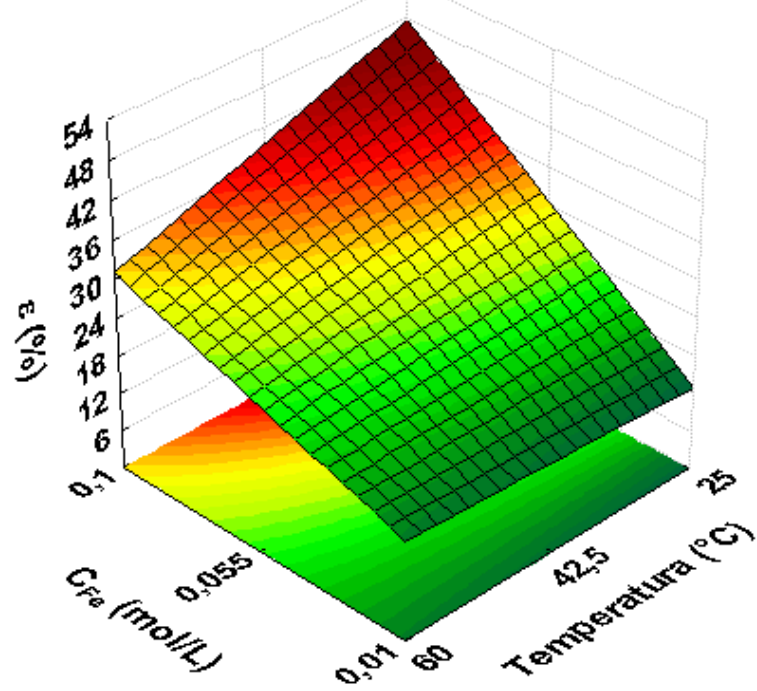

As interações entre as concentrações de $\mathrm{FeSO}_{4}$ e a temperatura sugerem $25{ }^{\circ} \mathrm{C}$ como a temperatura em que se obtém maiores eficiências de deposição.

$\mathrm{Na}$ Figura 4 estão apresentadas as interações entre a variação de concentração de sulfato de ferro e a variação da densidade de corrente elétrica, tendo como resposta a eficiência de deposição. Pela superfície de resposta da Figura 4, a interação entre a concentração de $\mathrm{FeSO}_{4}$ e a densidade de corrente sugere que a maior densidade de corrente não influencia os valores de eficiência de deposição.
Figura 4 - Superfície de resposta da eficiência de deposição em função da densidade de corrente e da concentração de sulfato de ferro

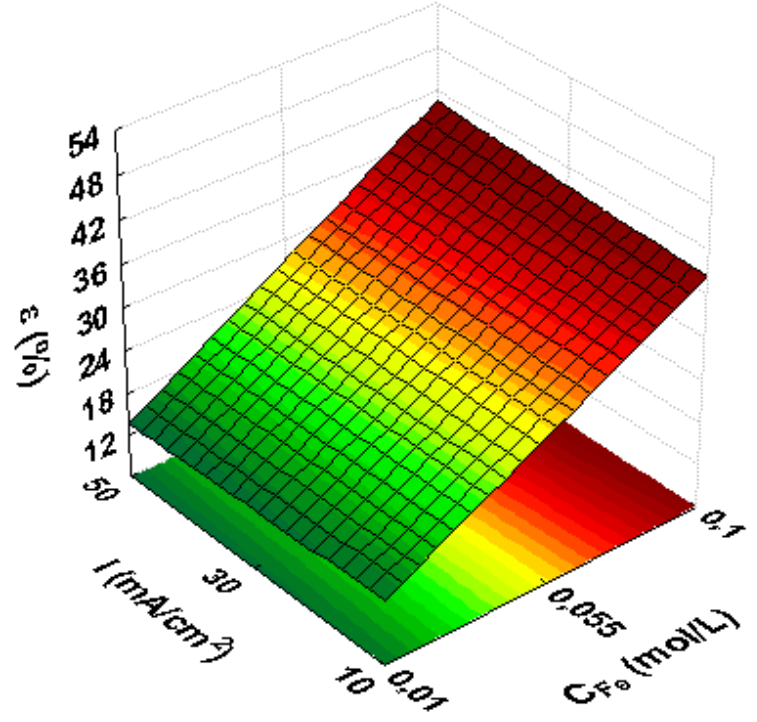

Os maiores valores de concentração de $\mathrm{FeSO}_{4}$ favoreceram as maiores eficiências de deposição, conforme as Figuras 3 e 4.

Os resultados de microscopia eletrônica de varredura indicaram a presença de microfissuras nas ligas obtidas, conforme pode ser observado na Figura 5.

Figura 5 - Topografia da liga com aumento de 5.000 vezes

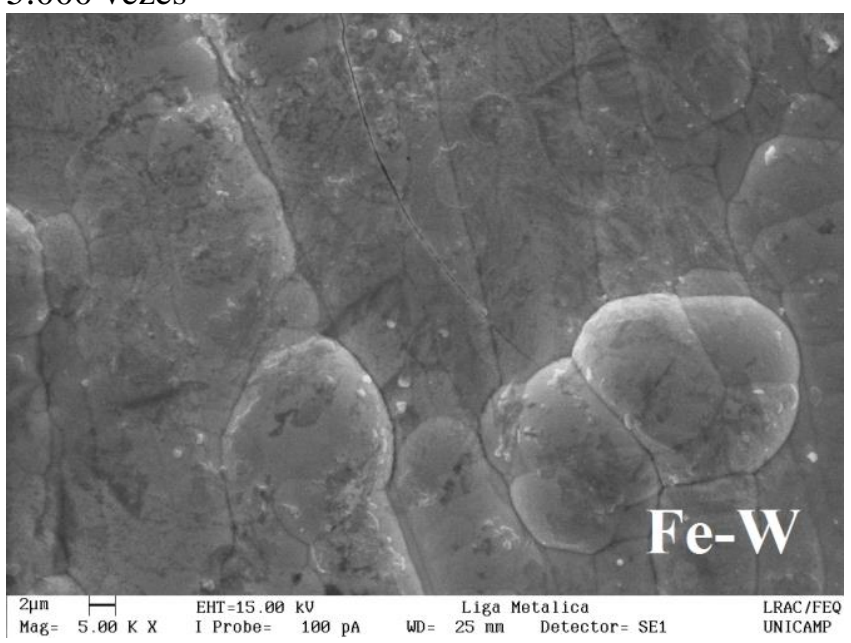

$\mathrm{Na}$ Figura 5, é possível observar também a presença de bolhas de hidrogênio presas entre a liga e o substrato, que surgiram 
possivelmente devido à acidez do banho. Ambos esses fatores fragilizam o material e facilitam a sua corrosão. As condições do banho e de eletrodeposição podem ser melhoradas e otimizadas com o intuito de obter ligas mais resistentes.

$\mathrm{O}$ resultado da análise de DRX mostrado na Figura 6 indica que a liga, por apresentar a formação de uma banda larga de difração, é predominantemente amorfa.

Santana, Campos e Prasad (2007) em um estudo com a liga de Fe-W-B obtiveram um resultado de DRX bem próximo do encontrado neste trabalho. Esses autores concluíram a partir da análise de DRX que a liga de Fe-W-B apresenta baixa cristalinidade.

Além disso, a faixa de ângulo de difração que contém o pico de maior intensidade, apresentada na Figura 6 , foi também similar ao obtido pelo trabalho de Santana, Campos e Prasad (2007).

Figura 6 - DRX da liga de Fe-W

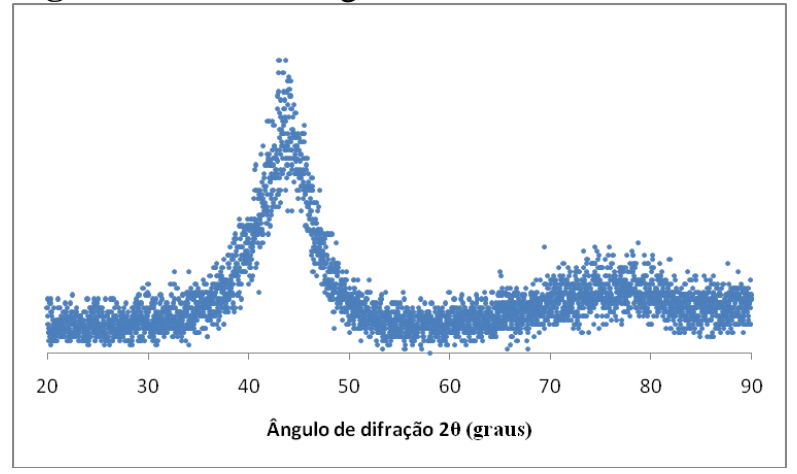

Como ligas amorfas em geral são mais resistentes à corrosão que ligas cristalinas, o resultado da análise de DRX é um bom indício para as ligas depositadas em relação à resistência corrosiva.

A análise de FTIR, apresentada na Figura 7, não apresentou absorbância significativa em toda a faixa de comprimento de onda em que foi realizado o teste. Os sinais apresentados na Figura 7 são ruídos. Dessa forma, a liga não apresenta compostos orgânicos e nem água de cristalização. Com isso, a liga obtida é pura. Essa é uma característica que confere resistência à corrosão para esse material, uma vez que a presença de impurezas provoca o surgimento de pilhas de ação local que corroem a liga.

Figura 7 - Resultado do FT-IR para a liga obtida

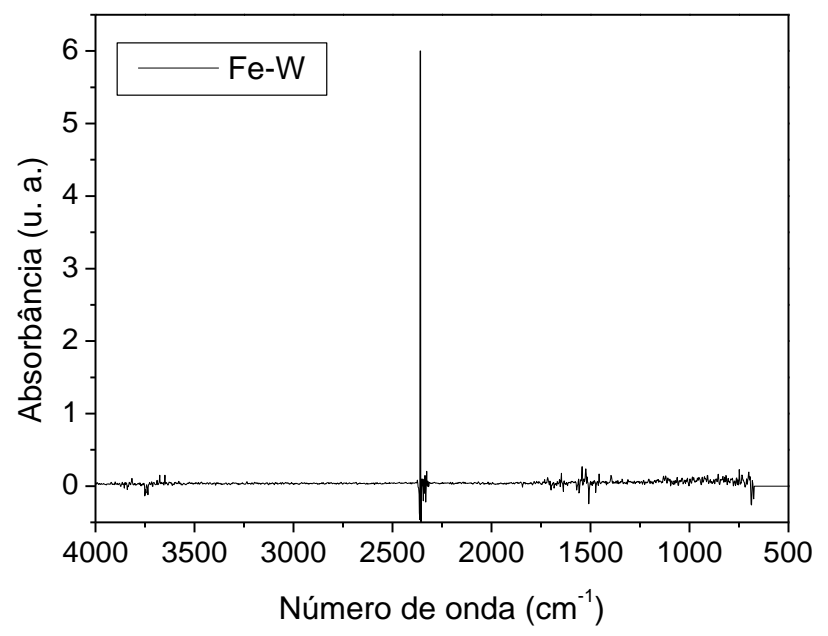

\section{CONCLUSÃO}

De forma geral, maiores eficiências foram obtidas para maiores concentrações de ferro e menores valores de densidade de corrente elétrica e temperatura. A maior eficiência de deposição para a liga de $\mathrm{Fe}-\mathrm{W}$ foi de aproximadamente $50 \%$, obtida na condição de $0,1 \mathrm{~mol} / \mathrm{L}$ de sulfato de ferro, densidade de corrente de $10 \mathrm{~mA} / \mathrm{cm}^{2}$ e temperatura de $25^{\circ} \mathrm{C}$. Pela caracterização das ligas constatou-se que elas apresentam estrutura predominantemente amorfa e são puras. Essas são boas características que elas apresentam, pois indicam que as ligas podem ser resistentes à corrosão. Os resultados de microscopia eletrônica de varredura mostraram que o material apresenta fissuras e bolhas em sua estrutura.

\section{NOMENCLATURA}

$m$ - massa do revestimento em gramas [g]

$t$ - tempo de deposição em segundos [s]

$i$ - corrente total usada em Ampère [A] 
$w_{j}$ - fração mássica de metal $j$ na liga dada por EDX

$n_{j}$ - número de elétrons transferido por cada átomo de metal $j$

$M_{j}$ - massa atômica do metal $j \mathrm{em} \mathrm{g} / \mathrm{mol}$

$F$ - constante de Faraday, 96.485

Coulomb/mol

$\mathrm{C}_{\mathrm{Fe}}$ - concentração de ferro no banho em $\mathrm{mol} / \mathrm{L}$

$\mathrm{I}$ - densidade de corrente elétrica em $\mathrm{mA} / \mathrm{cm}^{2}$

$\mathrm{T}$ - temperatura em ${ }^{\circ} \mathrm{C}$

\section{REFERÊNCIAS}

BHATTARAI, J.; AKIYAMA, E.; HABAZAKI, H.; KAWASHIMA, A.; ASAMI, K.; HASHIMOTO, K. Electrochemical and XPS studies on the passivation behavior of sputter-deposited WCr Alloys in $12 \mathrm{M} \mathrm{HCl}$ solution. Corrosion Science, v. 40, p. 155-175, 1998.

BRENNER, A. Electrodeposition of Alloys. New York: Academic Press, v. 2, 1963.

DELPHINE, S. M.; JAYACHANDRAN, M.; SANJEEVIRAJA, C. Pulsed electrodeposition and characterisation of tungsten diselenide thin films. Materials Chemistry and Physics, v. 81, p. 78-83, 2003.

DONTEN, M.; CESIULIS, H.; STOJEK, Z. Electrodeposition and properties of Ni-W, $\mathrm{Fe}$ $\mathrm{W}$ and Fe-Ni-W amorphous alloys. A comparative study. Electrochimica Acta, v. 45, p. 3389-3396, 2000.

SAKITA, A. M. P.; PASSAMANI, E. C.; KUMAR, H.; CORNEJO, D. R.; FUGIVARAS, C. S.; NOCE, R. D.; BENEDETTI, A. V. Influence of current density on crystalline structure and magnetic properties of electrodeposited Co-rich CoNiW alloys. Materials Chemistry and Physics, v. 141, p. 576-581, 2013.
SANTANA, R. A. C.; CAMPOS, A. R. N.; PRASAD, S. Otimização do Banho Eletrolítico da liga $\mathrm{Fe}-\mathrm{W}-\mathrm{B}$ resistente à corrosão. Química Nova, v. 30, n. 2, p. 360365, 2007.

SANTANA, R. A. C.; PRASAD, S.; SANTANA, F. S. M. Revestimento Eletrolítico com uma liga amorfa de Ni-W-B, resistente à corrosão e ao desgaste. Eclética Química, v. 28, p. 69-76, 2003.

THARAMANI, C. N.; PARTHASARATHI, B.; JAYARAM, V.; BEGUM, N. S.; MAYANNA, S. M. Studies on electrodeposition of Fe-W alloys for fuel cells applications. Applied Surface Science, v. 253, p. 2031-2037, 2006.

\section{AGRADECIMENTOS}

À FAPESP e ao $\mathrm{CNPq}$ pelo apoio financeiro. 